\title{
Coincidence detection in single dendritic spines mediated by calcium release
}

\author{
Samuel S.-H. Wang ${ }^{1,2,3}$, Winfried Denk ${ }^{1,2}$ and Michael Häusser ${ }^{1,4}$ \\ 1 Biological Computation Research Department, Bell Laboratories, Lucent Technologies, 600 Mountain Avenue, Murray Hill, New Jersey 07974, USA \\ 2 Department of Biomedical Optics, Max Planck Institute for Medical Research, Jahnstraße 29, D-69120 Heidelberg, Germany \\ 3 Present address: Department of Molecular Biology, Princeton University, Princeton, New Jersey 08544, USA \\ ${ }^{4}$ Department of Physiology, University College London, Gower Street, London WC1E 6BT, UK \\ Correspondence should be addressed to M.H. (m.hausser@ucl.ac.uk)orW.D. (winfried_denk@mpimf-heidelberg.mpg.de)
}

Cerebellar long-term depression (LTD) is a calcium-dependent process in which coincident activity of parallel fiber (PF) and climbing fiber (CF) synapses causes a long-lasting decrease in PF synaptic strength onto Purkinje cells. Here we show that pairing CF activation with bursts of PF activity triggers large $(>10 \mu \mathrm{M})$ calcium signals in Purkinje cell dendrites. When PFs are densely activated, signals span whole dendritic branchlets and are mediated by voltage-dependent calcium entry. When PFs are sparsely activated, however, signals are restricted to single spines and blocked by metabotropic glutamate receptor antagonists. Single-spine signals and sparse-stimulation LTD are also blocked by thapsigargin, indicating that calcium must be released from stores. Single-spine signals and sparse-stimulation LTD are greatest when PF activation precedes the CF activation within 50-200 ms. This timing rule matches the properties of several forms of motor learning, providing a link between behavior and functional properties of cerebellar synaptic plasticity.

Central to understanding learning mechanisms at a synaptic level is the idea that lasting functional change can be driven by the coincidence of multiple signals at a single synaptic site ${ }^{1}$. One candidate for such a change is long-term depression of the parallel fiber input to cerebellar Purkinje cells, a form of synaptic plasticity that is thought to underlie several forms of associative motor learning $^{2}$. LTD is induced by coincident activation of PF and CF synaptic inputs, and can last from hours to days ${ }^{2,3}$.

Although LTD has been extensively studied, the identity of the coincidence detection mechanism(s) triggered by conjunctive activation of PF and CF synapses is still controversial ${ }^{4}$. One second messenger, cytosolic calcium $\left(\mathrm{Ca}^{2+}\right)$, is both necessary ${ }^{5}$ and sufficient ${ }^{6}$ (L. Khiroug, G. Ellis-Davies \& G. J. Augustine, Soc. Neurosci. Abstr. 25, 397.3, 1999) to induce a depression of synaptic strength. This indicates that $\mathrm{Ca}^{2+}$ is a critical link in the induction of LTD. However, in contrast to most other synapses that show $\mathrm{Ca}^{2+}$-dependent associative plasticity, PF synapses lack postsynaptic NMDA receptors, which allow $\mathrm{Ca}^{2+}$ to enter neurons in response to the simultaneous presence of glutamate and depolarization (for review, see ref. 1).

Purkinje cells do, however, possess two other molecular mechanisms that could detect conjunctive $\mathrm{PF}$ and $\mathrm{CF}$ activation to generate a $\mathrm{Ca}^{2+}$ signal. The first of these is the inositol-1,4, 5-trisphosphate $\left(\mathrm{IP}_{3}\right)$ receptor ${ }^{7}$, which is synergistically coactivated $^{8}$ by $\mathrm{IP}_{3}$ and $\mathrm{Ca}^{2+}$. The $\mathrm{IP}_{3}$ receptor controls $\mathrm{Ca}^{2+}$ release from the endoplasmic reticulum and is present in high concentrations in both spines and shafts of Purkinje cell dendrites ${ }^{9}$. $\mathrm{IP}_{3}$ could be formed via the activation of metabotropic glutamate receptors (mGluR) by glutamate released from PF terminals ${ }^{10-12}$. The source of $\mathrm{Ca}^{2+}$ could be voltage-gated $\mathrm{Ca}^{2+}$ channels, which are known to be located on PF spines ${ }^{13}$, and may even be colocalized with the $\mathrm{IP}_{3}$ receptor on a molecular scale ${ }^{14}$. The depolarization necessary for activation of these $\mathrm{Ca}^{2+}$ channels could be provided by the complex spike that is triggered by $\mathrm{CF}$ input ${ }^{15}$. This mechanism, therefore, predicts that the combination of $\mathrm{CF}$ and $\mathrm{PF}$ inputs should generate a supralinear $\mathrm{Ca}^{2+}$ signal in $\mathrm{PF}$ spines ${ }^{7}$.

A second potential coincidence detection mechanism uses the voltage-gated $\mathrm{Ca}^{2+}$ channels in PF spines ${ }^{13}$. Because the channel activation curve is highly nonlinear, even a small local depolarization resulting from activation of AMPA channels at the PF synapse ${ }^{16}$ could combine with the depolarization by the complex spike to cause supralinear $\mathrm{Ca}^{2+}$ influx.

The involvement of release through $\mathrm{IP}_{3}$ receptors in the LTD induction pathway is supported by experiments demonstrating that blockers of $\mathrm{Ca}^{2+}$ release inhibit $\mathrm{LTD}^{6}$, and that $\mathrm{IP}_{3}$ uncaging can cause a form of $\mathrm{LTD}^{6,11}$. The metabotropic pathway is implicated because LTD induction can be prevented by mGluR antagonists ${ }^{17}$ (but see also ref. 4), and is impaired in a genetic knockout of mGluR1 receptors ${ }^{18}$.

To test whether there is indeed $\mathrm{Ca}^{2+}$-based coincidence detection, as indirectly suggested by these previous findings, we used two-photon laser scanning microscopy ${ }^{19}$ (2PLSM) of fluorescent $\mathrm{Ca}^{2+}$ indicators to observe signals in individual PF dendritic spines $^{13}$. We found that conjunctive activation of CF inputs and physiologically realistic PF stimuli indeed generated supralinear $\mathrm{Ca}^{2+}$ signals, which, under certain conditions, were confined to single spines. We then compared the temporal requirements for $\mathrm{Ca}^{2+}$ supralinearity and induction of LTD with the temporal requirements found in a number of motor learning experiments that involve the cerebellum. 
Fig. 1. Supralinear $\mathrm{Ca}^{2+}$ signals in Purkinje cell dendrites and spines evoked by coincident synaptic input. (a) Purkinje neuron filled with Magnesium Green through a patch pipette (bottom), with glass pipettes for PF and CF activation (straight white outlines). (b) Peak $\left[\mathrm{Ca}^{2+}\right]_{i}$ increases in a Purkinje neuron spiny branchlet in response to 8 PF stimuli delivered in conjunction with a single CF stimulus. Bottom

a

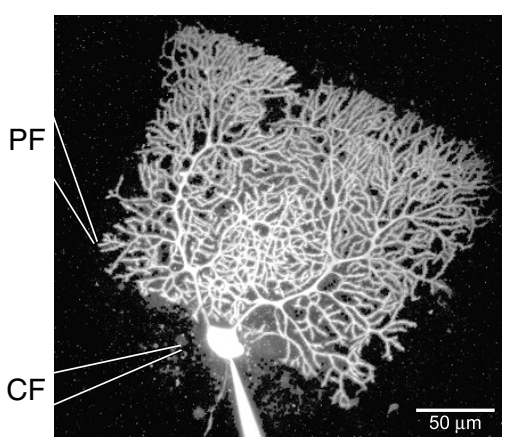

b

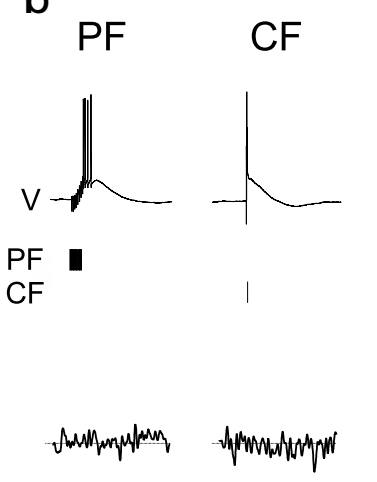

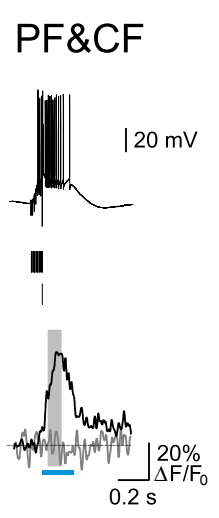
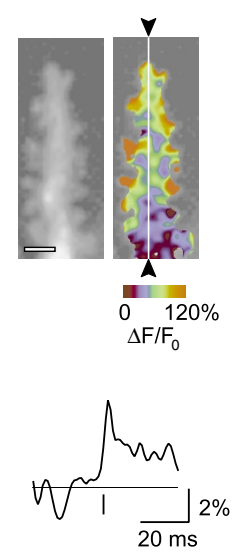

traces (left), fluo rescence changes in a line scan along the dendritic shaft, with corresponding voltage traces (V, top). Location of the line scan, arrowheads in the pseudocolor image. Under 'PF\&CF', bottom, the black trace indicates the coincidence signal, the gray trace indicates the linear sum of PF and CF fluorescence signals, the shaded band on the fluorescence trace indicates the time interval used to generate the pseudocolor image, and the blue horizontal bar indicates the 200-ms interval over which response amplitude and supralinearity were calculated. Trace on right, comparison (note different scaling) of the time course of a typical CF-evoked $\mathrm{Ca}^{2+}$ response (average of 50 trials taken in 2 spines and filtered at $5 \mathrm{~ms}$ ).

\section{RESULTS}

\section{Supralinear calcium signals}

Purkinje cells were filled in whole-cell patch recordings (Fig. 1a) with the low-affinity $\mathrm{Ca}^{2+}$ indicator Magnesium Green (250-500 $\mu \mathrm{M}$; estimated $\left.\mathrm{K}_{\mathrm{D}}, 19 \mu \mathrm{M}^{20,21}\right)$ to avoid dye saturation and the changes in the intracellular calcium concentration $\left(\left[\mathrm{Ca}^{2+}\right]\right)$ dynamics that occur as a result of substantially altering the intracellular $\mathrm{Ca}^{2+}$ buffer capacity with high-affinity $\mathrm{Ca}^{2+}$ indicators $^{22}$. Although low-affinity indicators are less sensitive to small $\left[\mathrm{Ca}^{2+}\right]$ changes, they do allow the quantification of $\left[\mathrm{Ca}^{2+}\right]$ transients in the micromolar range ${ }^{21}$. As an assay of $\left[\mathrm{Ca}^{2+}\right]$ levels reached in response to synaptic stimulation, we measured the mean relative fluorescence increase $\left(\Delta \mathrm{F} / \mathrm{F}_{0}\right)$ in the $200 \mathrm{~ms}$ following the end of stimulation. We stimulated PF inputs (second EPSP, 1.5 to $7.8 \mathrm{mV} ; 4.2 \pm 0.4 \mathrm{mV}$, mean \pm s.e.m., $n=27$ ) at physiologically plausible ${ }^{23}$ frequencies ( 3 to 10 stimuli at $100 \mathrm{~Hz}$ ). Com- bining PF stimulation with $\mathrm{CF}$ activation evoked large $\mathrm{Ca}^{2+}$ signals in both spines (Fig. 1b;30.4 $\left.\pm 7.4 \% \Delta \mathrm{F} / \mathrm{F}_{0}\right)$ and shafts $(19.0 \pm$ $\left.4.1 \% \Delta \mathrm{F} / \mathrm{F}_{0}, n=27\right)$ of spiny branchlets. Activation of the PF inputs alone generated smaller fluorescence transients $(5.5 \pm 1.6 \%$ $\Delta \mathrm{F} / \mathrm{F}_{0}, 16$ spines). Single stimuli to the CF generated complex spikes in the voltage recording and fluorescence transients in the Purkinje cell. These were much smaller $\left(0.8 \pm 0.3 \% \Delta \mathrm{F} / \mathrm{F}_{0}\right.$ in spines, 200-ms window, $n=22$ ) but still corresponded to $\left[\mathrm{Ca}^{2+}\right]$ changes of about $150 \mathrm{nM}$; both this averaged response and the peak transient (Fig. 1b) are consistent with previous measurements of $\left[\mathrm{Ca}^{2+}\right]$ during CF activation ${ }^{15}$ (M. H., G. Parésys \& W. D., Soc. Neurosci. Abstr. 23, 781.5, 1997) and $\mathrm{Ca}^{2+}$ spikes ${ }^{15,24}$.

Coincidence $\mathrm{Ca}^{2+}$ signals were thus much larger than the linear sum of responses to either PF or CF activation alone; their peaks reached values above $10 \mu \mathrm{M}$ (Fig. 1b). This supralinearity was quantified as the ratio of the coincidence response to the

Fig. 2. Supralinear $\mathrm{Ca}^{2+}$ signals in single spines. (a) Top, monitored spines, within gray frames. Traces, somatic voltage (V) and fluorescence responses (spine 1 and spine 2) under three stimulus conditions: 3 PF stimuli (within vertical shaded band) at $100 \mathrm{~Hz}$ (left), and an identical PF burst combined with CF activation (long vertical black lines) either 60 ms before (middle) or $150 \mathrm{~ms}$ after (right) the beginning of the PF burst. The response to conjunctive stimulation is indicated by black traces in the center and right columns; response to PF alone is indicated by the black traces on the left column and by the gray traces. (b) Average time course of supralinear $\mathrm{Ca}^{2+}$ signals from 14 spines. The responses to separate activation of PF and CF inputs, and their linear sum, are also shown. Horizontal bars, bottom, duration of PF or CF stimulation. (c) Relationship between type of the $\mathrm{Ca}^{2+}$ responses and PF-EPSP size. Cumulative histogram of EPSP size (second EPSP in the train) in response to $2 \mathrm{PF}$ stimuli delivered at $100 \mathrm{~Hz}$, sorted by whether the $\mathrm{Ca}^{2+}$ responses to coincident PF\&CF activation were limited to spines (sparse PF stimulation, SPFS) or spread into branchlets (dense PF stimulation, DPFS).
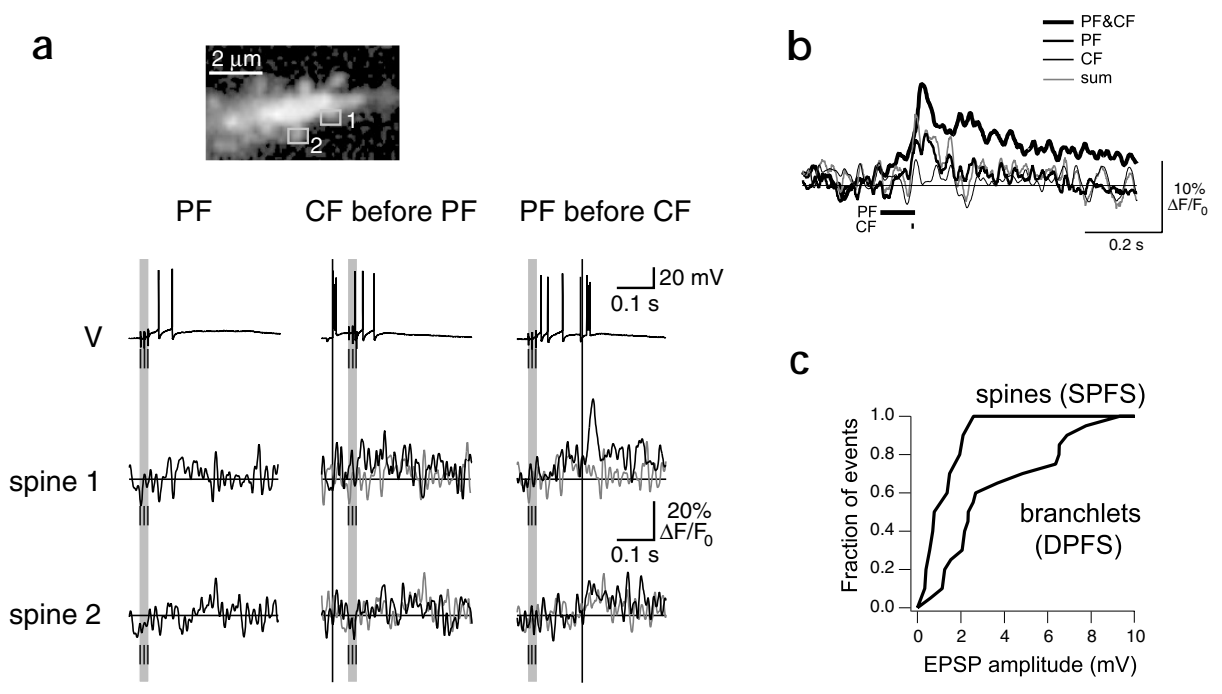

C

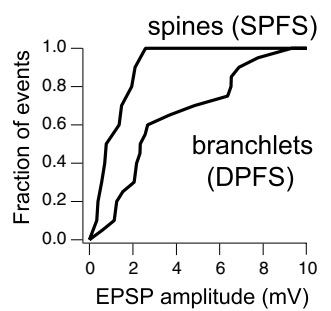


Fig. 3. D iscriminating coincidence evoked spine and branchlet $\mathrm{Ca}^{2+}$ signals by hyperpolarization. (a, b) Block of branchlet coincidence signals by hyperpolarization. (a) Top, coincident delivery of 7 PF stimuli with 1 CF stimulus caused a branchlet-wide signal. Images were taken at $64 \mathrm{~ms}$ intervals and aligned to match the voltage trace below. Bottom, somatic injection of a $6 \mathrm{~ms},-10 \mathrm{nA}$ current pulse $15 \mathrm{~ms}$ after the CF stimulus caused a hyperpolarization of tens of millivolts (voltage trace) and blocked the $\mathrm{Ca}^{2+}$ signal in all but two spines (indicated by white arrowheads in image sequence). (b) Similar experiment to (a), but with PF stimuli starting at $70 \mathrm{~ms}$ before the CF stimulus. Injection of a $60 \mathrm{~ms},-1 \mathrm{nA}$ current pulse during PF stimulation hyperpolarizes the neuron (blue trace) and blocks the $\mathrm{Ca}^{2+}$ signal in the dendritic shaft, but spares the response in three spines (white arrowheads). The somatic CF voltage response is unaffected by the hyperpolarization. (c) Spine supralinearity survives when branchlet signals are suppressed by hyperpolarization. Each symbol represents the $\mathrm{Ca}^{2+}$ signal in spines where the corresponding branchlet signal was suppressed by hyperpolarization (timing condition as in a). A subset of spines (filled symbols) remained at least $20 \%$ supralinear relative to PF stimulation alone. (d) Comparison of the coincidence response in the presence and absence of hyperpolarization. Many of the non-supralinear spines are suppressed by hyperpolarization, but the spines selected in (a) (filled symbols) are relatively unaffected.

sum of the responses to PF and CF stimulation alone (see Methods). Supralinearity of the $\mathrm{Ca}^{2+}$ signals was observed in spines (supralinearity $8.2 \pm 2.2, n=12 ; p<0.01$ ) as well as in dendritic shafts (supralinearity $4.5 \pm 1.3, n=16$ ).

The strong stimuli used in the previous experiment might activate a large fraction of PFs passing in the vicinity of the stimulation electrode ('dense parallel fiber stimulation,' DPFS) and may not, therefore, be representative of the natural activity pattern of parallel fibers. We thus reduced the stimulation intensity to levels that activate only small numbers of synaptic inputs ('sparse parallel fiber stimulation,' SPFS). Under SPFS, we frequently saw coincidence signals confined to single spines (Fig. 2a and b; second EPSP in train 0.3 to $2.6 \mathrm{mV}$; mean $1.2 \pm 0.2 \mathrm{mV}, n=19$; EPSP size distribution for SPFS and DPFS were different, leading to branchlet signals; Kolmogorov-Smirnov test, $p<0.05)$. The peak spine $\left[\mathrm{Ca}^{2+}\right]$ changes with SPFS were somewhat smaller than peak spine changes observed during branchlet-wide coincidence events $\left(12.4 \pm 2.0 \% \Delta \mathrm{F} / \mathrm{F}_{0}, p<0.05\right)$ but the $\mathrm{Ca}^{2+}$ signals remained significantly supralinear (supralinearity $3.5 \pm 1.1, p<0.01$ ). Supralinearity confined to spines was observed for short high-frequency bursts (3-10 PF stimuli at $100 \mathrm{~Hz}$, data not shown), demonstrating that a single-spine form of coincidence detection can be evoked by combining CF activation with realistic temporal pattern ${ }^{23}$ of $\mathrm{PF}$ activity. Supralinear $\mathrm{Ca}^{2+}$ signals were sensitive to the temporal order of the two inputs, with larger responses observed with PF preceding CF activation (Fig. 2a; see below).

\section{Mechanisms of calcium supralinearity}

The critical contribution of the CF input to coincidence detection could be mediated either by the widespread depolarization in the dendritic tree during a complex spike ${ }^{25}$ or by the consequent $\mathrm{Ca}^{2+}$ entry ${ }^{15}$. To distinguish between $\mathrm{Ca}^{2+}$ entry and depolarization per se, Purkinje cells were hyperpolarized after $\mathrm{CF}$-induced $\mathrm{Ca}^{2+}$ entry was nearly complete. This was achieved by delivering hyperpolarizing current pulses $(-10 \mathrm{nA}, 3-6 \mathrm{~ms})$ 10-15 ms after CF activation, a time when $\mathrm{Ca}^{2+}$ entry is complete but residual depolarization persists ${ }^{15}$ (Fig. 1b). Such current pulses, which transiently hyperpolarize the soma and dendrites by
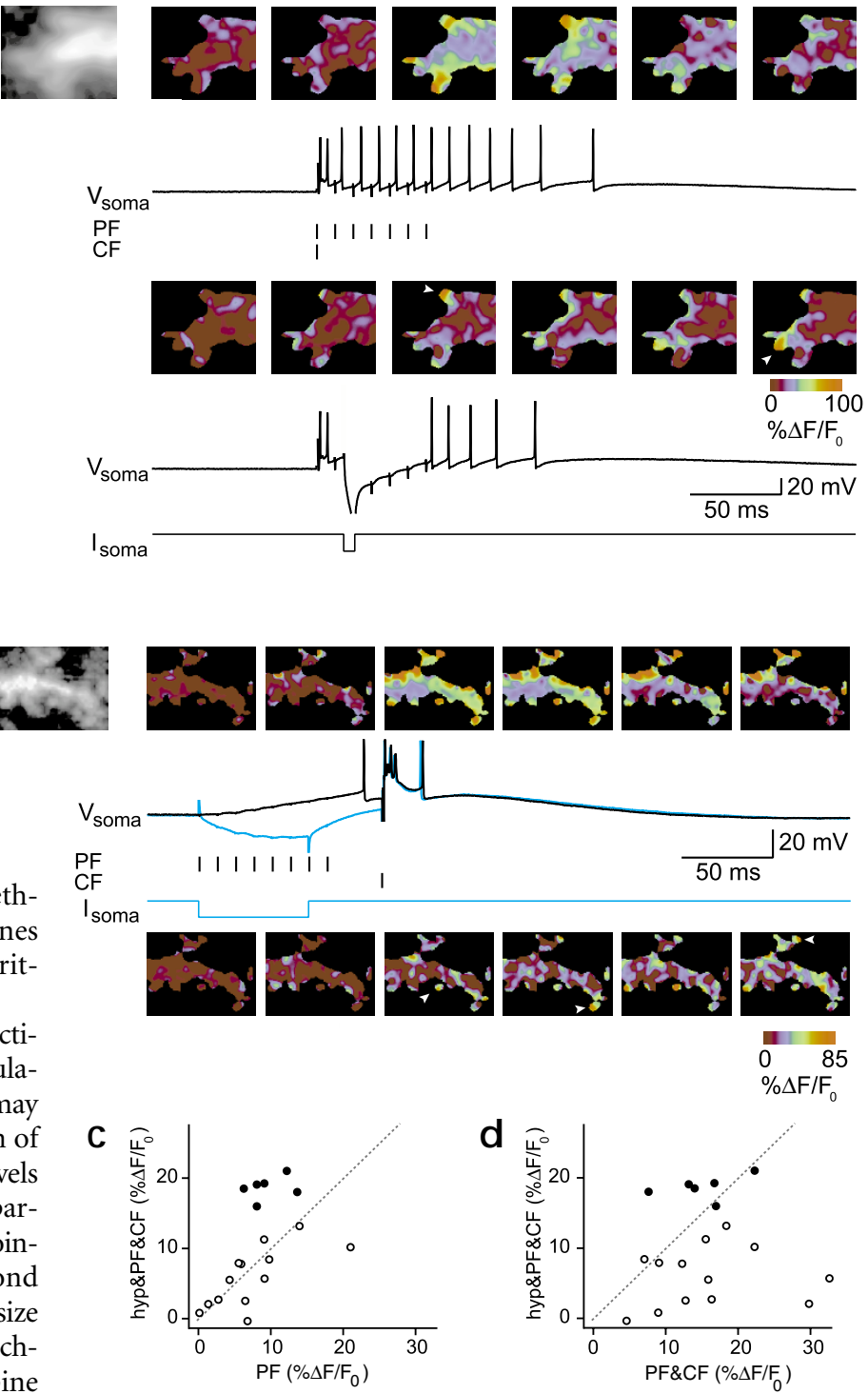

tens of millivolts ${ }^{26}$ (Fig. 3a), suppressed the coincidence-evoked supralinear $\mathrm{Ca}^{2+}$ signal in branchlets (DPFS, Fig. 3a, c and d; PF alone $3.1 \pm 1.8 \% \Delta \mathrm{F} / \mathrm{F}_{0}$; coincident stimulation $16.4 \pm 3.3 \% \Delta \mathrm{F} / \mathrm{F}_{0}$; coincident stimulation with hyperpolarizing pulse $3.7 \pm 0.5 \%$ $\Delta \mathrm{F} / \mathrm{F}_{0}, n=3$ ). Branchlet signals could also be suppressed if DPFS was initiated before the CF, using a hyperpolarizing current pulse during PF stimulation (Fig. 3b). Under this condition, the somatically recorded voltage response to CF stimulation was virtually unaltered by the preceding hyperpolarizing current injection (Fig. 3b, compare black and blue traces).

Conversely, strongly supralinear branchlet-wide $\left[\mathrm{Ca}^{2+}\right]$ responses could be evoked if the CF input were replaced by a somatic depolarizing current pulse ( $+0.4 \mathrm{nA}, 50 \mathrm{~ms})$. Such conditions are often used to evoke LTD in Purkinje cells ${ }^{4,27,28}$. Because depolarization can be used as a surrogate for CF activation of AMPA receptors ${ }^{16}$, we could test the ability of the AMPA/kainate receptor antagonist 6,7-dinitroquinoxaline-2,3dione (DNQX) to block branchlet coincidence signals mediated by PF activation. Application of DNQX (20-50 $\mu \mathrm{M}, n=3)$ reduced branchlet responses to $\mathrm{PF}$ stimulation alone $(7 \pm 3 \%$ $\Delta \mathrm{F} / \mathrm{F}_{0}$ control; $2 \pm 2 \% \Delta \mathrm{F} / \mathrm{F}_{0}$ in $\left.\mathrm{DNQX}\right)$, and blocked coincidence-evoked $\mathrm{Ca}^{2+}$ signals $\left(18 \pm 5 \% \Delta \mathrm{F} / \mathrm{F}_{0}\right.$ control coincidence 
Fig. 4. Metabotropic glutamate receptor requirements in coincidence evoked $\mathrm{Ca}^{2+}$ signals. Horizontal bars at bottom of figure denote duration of PF or CF stimulation. (a) Inhibition of spine signals by metabotropic glutamate receptor blockade. Single-spine coincidence signals (black traces, bottom) are blocked by local application of the metabotropic glutamate receptor antagonist (S)-4-carboxyphenylglycine (4-CPG, $1 \mathrm{mM})$. The gray traces in all panels of the bottom row denote the linear sum of PF and CF signals, and indicate that supralinearity was also blocked by 4-CPG. This effect was reversible after washout of the antagonist (right). Fluorescence traces, average of four experiments. (b) Branchlet signals (far right panels) are not affected by $4-C P G$. Fluorescence traces are averages of three different experiments. a
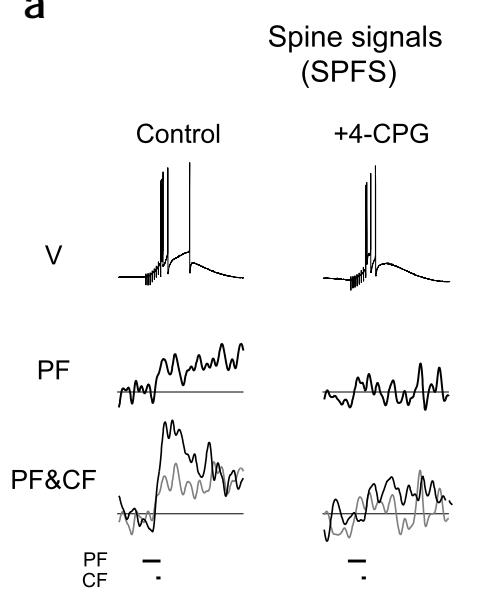

b

\section{Branchlet signals}

(DPFS)
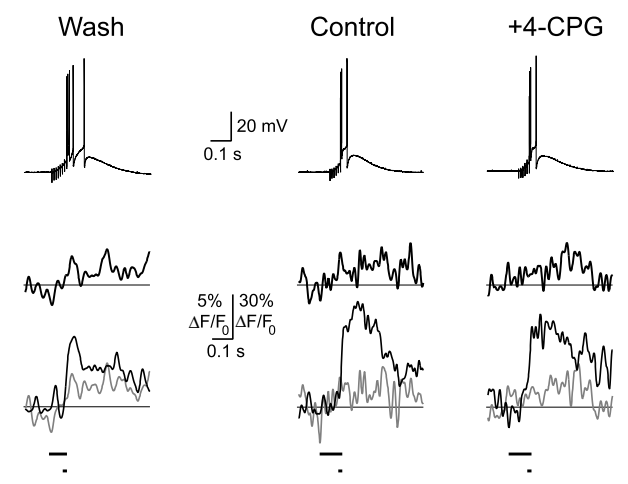

signal; $1.1 \pm 0.8 \% \Delta \mathrm{F} / \mathrm{F}_{0}$ in $\mathrm{DNQX}$; significant reduction, $p<0.025)$. These results indicate that depolarization by both the $\mathrm{PF}$ and CF inputs is necessary for generating branchlet-wide DPFS coincidence signals, and support a model in which a complex spike enhances local depolarization from DPFS, to augment the highly nonlinear activation of voltage-gated $\mathrm{Ca}^{2+}$ channels.

Even though hyperpolarization was able to suppress branchlet responses to coincident activation of PF and CF inputs, a supralinear calcium signal could often still be observed in some spines under these conditions (arrowheads, Fig. 3a and b). In the spines showing supralinearity, the response to coincident $\mathrm{PF}$ and $\mathrm{CF}$ stimulation with a hyperpolarizing pulse $\left(15 \pm 2 \% \Delta \mathrm{F} / \mathrm{F}_{0}\right.$, $n=6)$ was not reduced from the response to coincident stimulation alone ( $16 \pm 3 \% \Delta \mathrm{F} / \mathrm{F}_{0}, n=6$; Fig. $3 \mathrm{a}, \mathrm{c}$ and $\left.\mathrm{d}\right)$. These results indicate that single-spine coincidence detection does not require persistent depolarization by the complex spike.

The remaining plausible contribution of the CF input to coincidence detection is complex-spike-mediated $\mathrm{Ca}^{2+}$ entry ${ }^{10}$ acting as a co-activator of $\mathrm{IP}_{3}$ receptor channels ${ }^{7,8}$ to cause $\mathrm{Ca}^{2+}$ release, an effect that could be accentuated by buffer saturation ${ }^{29}$. We therefore applied compounds that block various steps along the $\mathrm{Ca}^{2+}$ release pathway. First, we applied the mGluR antagonist (S)-4-carboxyphenylglycine (4-CPG; $0.5-1.0 \mathrm{mM}$ ). Under conditions of single-spine coincidence detection (SPFS), 4-CPG reversibly inhibited both PF-alone $\mathrm{Ca}^{2+}$ signals ( $25 \pm 1 \%$ of control, $\left.n=4\right)$ and coincidence-evoked $\mathrm{Ca}^{2+}$ signals ( $25 \pm 16 \%$ of control) in single spines; the small remaining signal was linear (Fig. 4a). EPSPs were unchanged by $4-\mathrm{CPG}$, as measured by either the PF-alone EPSP (control, $1.6 \pm 0.5 \mathrm{mV}$; in $4-\mathrm{CPG}, 1.5 \pm 0.5 \mathrm{mV}$; not different, $p=0.5$ ) or the number of somatic sodium action potentials (APs) evoked by coincidence (control, $4.0 \pm 0.6 \mathrm{APs}$; in 4-CPG, $3.5 \pm$ 0.3 APs; not different, $p=0.3$ ). Unlike the spine signals, branchlet coincidence signals were unaffected by a metabotropic receptor antagonist (Fig. 4b; 4-CPG, response $92 \pm 10 \%$ of control, $n=3$ ). These results support a mechanism for single-spine supralinearity in which the PF pathway must activate mGluRs.

To identify the contribution of $\mathrm{Ca}^{2+}$ release from stores, we next blocked $\mathrm{Ca}^{2+}$ release with thapsigargin, an irreversible blocker of the endoplasmic reticulum family of $\mathrm{Ca}^{2+}$ pumps ${ }^{30}$. After application of thapsigargin $(2 \mu \mathrm{M})$ for 15-30 minutes, SPFS single-spine coincidence signals were reduced from $7.5 \pm 3.2 \% \Delta \mathrm{F} / \mathrm{F}_{0}$ to $2.2 \pm 1.4 \%$ $\Delta \mathrm{F} / \mathrm{F}_{0}\left(0.26 \pm 0.08\right.$ of control $n=3$; Fig. 5a). PF-only $\mathrm{Ca}^{2+}$ signals were nearly unchanged (normal, $1.2 \pm 0.6 \% \Delta \mathrm{F} / \mathrm{F}_{0}$; in thapsigargin, $1.0 \pm 0.3 \% \Delta \mathrm{F} / \mathrm{F}_{0}$ ), whereas the supralinearity factor was reduced from $7.1 \pm 1.7$ to $2.2 \pm 1.3$. In contrast, DPFS-induced branchlet signals persisted (before, $11.5 \pm 1.7 \% \Delta \mathrm{F} / \mathrm{F}_{0}$, in thapsigargin, $9.8 \pm$ $1.8 \% \Delta \mathrm{F} / \mathrm{F}_{0} ; 0.83 \pm 0.04$ of control, 4 branchlets; Fig. 5a). To confirm that $\mathrm{IP}_{3}$-mediated release does not contribute to branchlet signals, Purkinje cells were dialyzed with heparin, a competitive blocker of $\mathrm{IP}_{3}$ receptors ${ }^{6}$. Under these conditions, large supralinear $\mathrm{Ca}^{2+}$ signals were still observed with DPFS in both shafts $\left(9.6 \pm 1.4 \% \Delta \mathrm{F} / \mathrm{F}_{0}\right.$, supralinearity $\left.5.9 \pm 1.9, n=4\right)$ and spines $\left(8.2 \pm 0.9 \% \Delta \mathrm{F} / \mathrm{F}_{0}\right.$, supralinearity $\left.2.7 \pm 0.5, n=4\right)$. In a few experiments under SPFS plus CF stimulus conditions with heparin in the patch pipette, no responding spines were found (31 spines in 3 branchlets), as predicted by the $\mathrm{IP}_{3}$ hypothesis. However, we could not completely rule out that the spines where EPSCs were generated were out of the field of view. Finally, we compared the number of sodium APs evoked at the soma under the different stimulation conditions used. DPFS alone evoked 2.9 \pm 0.9 APs, whereas DPFS paired with CF activation evoked 3.6 $\pm 1.0 \mathrm{APs}$, a moderate increase ( $n=22$; change, $+0.7 \pm 0.5 \mathrm{APs} ; p=0.1$ ), which is consistent with the voltage dependence of branchlet signals. For SPFS we did not find a difference between PF alone (1.73 $\pm 0.54 \mathrm{APs})$ and paired activation ( $1.67 \pm 0.48 \mathrm{APs} ; n=16, p=0.6)$, which is consistent with the $\mathrm{IP}_{3}$ hypothesis of single spine coincidence detection and with previous evidence $e^{25,26}$ that dendritic depolarization is only weakly coupled to somatic membrane potential. Taken together, these results indicate that $\mathrm{Ca}^{2+}$ release is required for spine coincidence signals, but not for branchlet coincidence signals.

\section{Timing dependence of supralinear spine calcium signals}

To determine the timing requirements for supralinear 'summation' of $\mathrm{Ca}^{2+}$ signals, we varied the interval between the start of the PF burst ( $\Delta t=0$; Figs. $2 \mathrm{a}$ and $6 \mathrm{a})$ and CF firing. The largest $\mathrm{Ca}^{2+}$ signals were observed when $\mathrm{PF}$ and $\mathrm{CF}$ activity were approximately, but not exactly, synchronous (Figs. $2 \mathrm{a}$ and $\mathbf{6 b}$ ). For optimal timing for the spine signals, the PF activity had to begin before the CF complex spike (Figs. 2a and 6a). When we fitted the pooled transient (200 ms window) $\left[\mathrm{Ca}^{2+}\right]$ data with a Gaussian, we found an optimal $\Delta t$ of $+64 \pm 12$ ms with a half-maximal width of $94 \pm 37 \mathrm{~ms}$. When, alternatively, response amplitude was measured by integrating the total response from the time of the first stimulus to $500 \mathrm{~ms}$ after the last stimulus, the Gaussian fit to these data (Fig. 6c) showed a comparable offset $(\Delta t=+92 \pm$ $37 \mathrm{~ms})$ but a much larger half-maximal width $(212 \pm 85 \mathrm{~ms})$ than the transient measurement. By both measures, the largest nonlinearity occurred when the CF fired near the end of the PF burst. 


\section{articles}

a
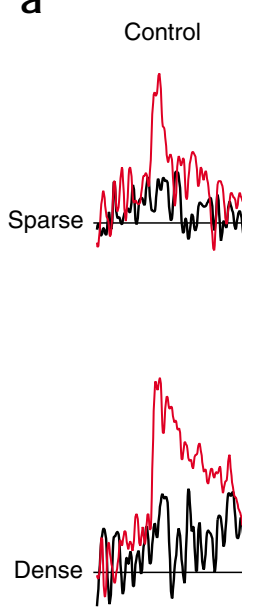

b

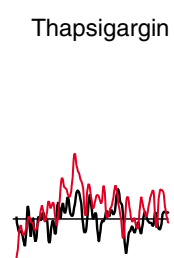

$\int_{0.1 \mathrm{~s}} \frac{10 \%}{\Delta \mathrm{F} / \mathrm{F}_{0}}$

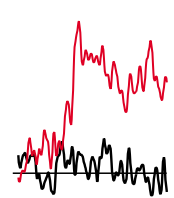

C
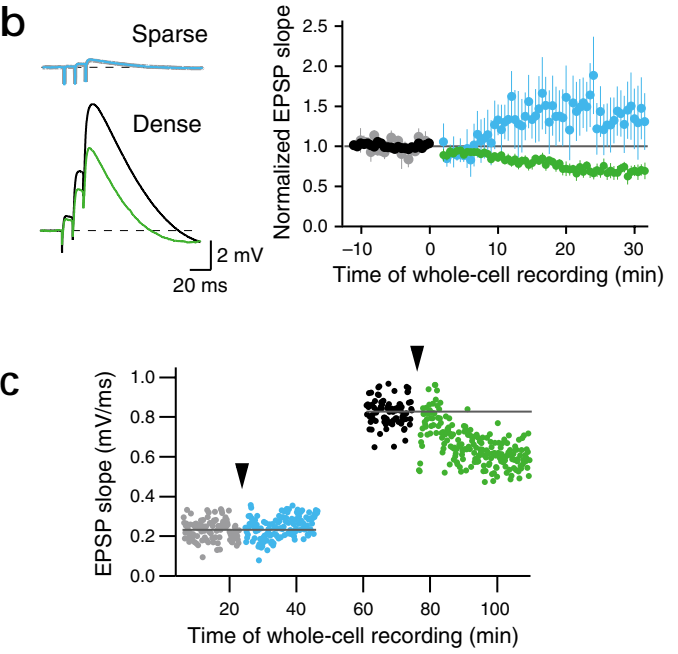

d

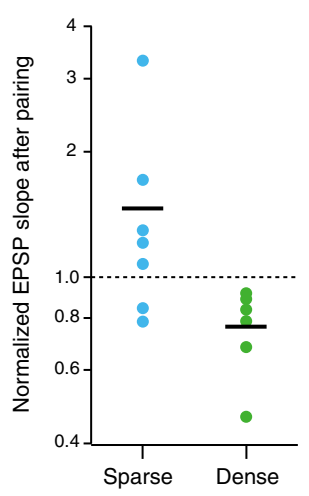

Fig. 5. Block of spine signals and weak-stimulus LTD by thapsigargin. (a) $\mathrm{Ca}^{2+}$ signals measured in line-scan mode in a single spine (top) resulting from SPFS-CF coincidence and in its parent spiny branchlet (bottom) resulting from DPFS-CF coincidence. Signals in response to PF stimulation alone (black traces) and conjunctive PF and CF stimulation (red traces) are shown, in control conditions and in the presence of thapsigargin ( $2 \mu \mathrm{M})$. Thapsigargin inhibits the supralinear $\mathrm{Ca}^{2+}$ signal in response to SPFS, but not DPFS. (b-d) Induction of synaptic plasticity in the presence of thapsigargin $(2 \mu \mathrm{M})$. Blue symbols, EPSPs taken following induction by pairing CF stimuli with SPFS. Green symbols, EPSPs taken following induction by pairing CF stimuli with D PFS. Black symbols, EPSPs taken before induction by pairing CF stimuli with SPFS. G ray symbols, EPSPs taken before induction by pairing CF stimuli with DPFS. (b) Left, representative EPSPs taken before (black and gray traces) and after (green and blue traces) the induction protocol. EPSPs before and after induction were superimposable when CF stimuli were paired with SPFS. Right, mean time course of PF synaptic strength following induction by pairing CF stimuli with either SPFS (blue symbols) or DPFS (green symbols). (c) An experiment in which pairing of CFs with SPFS (left arrowhead) was followed, in the same cell, by pairing with DPFS (right arrowhead). (d) The net change in synaptic efficacy, measured 20 min after induction for all experiments performed in the presence of thapsigargin. Horizontal bars, means.

DPFS-evoked branchlet $\left[\mathrm{Ca}^{2+}\right]$ coincidence signals showed a much broader timing window $(\Delta t=-3 \pm 43 \mathrm{~ms}$, width $=460 \pm$ $140 \mathrm{~ms}$, integrated total response; data not shown).

\section{Timing dependence and pharmacology of SPFS-LTD}

If the supralinear $\mathrm{Ca}^{2+}$ signals we observed are indeed the trigger for LTD, then we would expect to find a similarly offset timing dependence for LTD induction. We therefore did LTD experiments, using SPFS. To ensure SPFS conditions, stimulus intensity was adjusted to give an EPSP amplitude of $<1 \mathrm{mV}$ for the second stimulus, an amplitude at which supralinear $\mathrm{Ca}^{2+}$ signals are almost completely restricted to single spines (Fig. 2c). Co-activation of $\mathrm{PF}$ and $\mathrm{CF}$ inputs produced a lasting depression of the $\mathrm{PF}$ response (Fig. $6 \mathrm{~d}$ and e; $0 \mathrm{~ms}$ interval, $-32 \pm 18 \%, p<0.05$ ), whereas activation of the PFs alone $(+4 \pm 6 \%$ increase, $n=3$, $p=0.3)$ or the CF alone $(+0.2 \pm 2.6 \%$ increase, $n=4, p=0.5)$ had no significant effect. The magnitude of the depression depended on the timing of CF and PF activation in a manner consistent with the timing dependence of supralinear spine $\mathrm{Ca}^{2+}$ signals (Fig. 6 b and c). In particular, the delivery of PF bursts $150 \mathrm{~ms}$ before, but not after, CF firing caused depression (+150 ms, $-27 \pm$ $15 \%, n=6 ;-150 \mathrm{~ms},+1 \pm 11 \%, n=4)$. More widely separated pairings also did not cause depression ( $-500 \mathrm{~ms},-10 \pm 6 \%, n=3$; $+500 \mathrm{~ms},+6 \pm 17 \%, n=3)$. This match in timing dependence supported the idea that supralinear $\mathrm{Ca}^{2+}$ signals are a necessary step in the induction of plasticity.

To further strengthen the link between the supralinear $\mathrm{Ca}^{2+}$ signals and synaptic plasticity, we took advantage of the ability of thapsigargin to discriminate between spine and branchlet $\left[\mathrm{Ca}^{2+}\right]$ supralinearity. During the induction period, CF activation was paired with either DPFS or SPFS. Under normal recording conditions, pairings with SPFS led to a decrease in PF transmission
$(-27 \pm 15 \%$ from baseline, $n=6)$. In the presence of thapsigargin, pairing with SPFS led, if anything, to an increase in PF transmission ( $+46 \pm 33 \%, n=7$, Fig. 5b-d; different from normal LTD, $p<0.05$ ). With DPFS (EPSP $>2 \mathrm{mV}$; Fig. $2 \mathrm{c}$ ), pairing still led to a decrease in PF transmission ( $-24 \pm 7 \%$ from baseline, $n=6$, Fig. $5 \mathbf{b}-\mathrm{d}$; not different from normal LTD, $p=0.4$ ). These results (summarized in Fig. 6e) show that $\mathrm{Ca}^{2+}$ release from stores is necessary for both spine $\mathrm{Ca}^{2+}$ coincidence signals and LTD under sparse stimulation (SPFS) conditions, but for neither branchlet $\mathrm{Ca}^{2+}$ signals nor LTD using dense stimulation (DPFS).

\section{Discussion}

We have shown that conjunctive activation of PF and CF inputs to Purkinje cells generates calcium signals in spines and dendrites greatly exceeding the linear sum of responses to the individual inputs. Our findings indicate that Purkinje cell dendrites are capable of at least two types of supralinear $\left[\mathrm{Ca}^{2+}\right]$ dynamics. These two types differ most obviously in their dependence on PF activity and in the spatial extent of the resulting $\mathrm{Ca}^{2+}$ signal. When small numbers of PFs are activated (sparse activation), supralinear $\mathrm{Ca}^{2+}$ signals are restricted to single spines, and depend on $\mathrm{Ca}^{2+}$ release from internal stores. When many neighboring PFs are activated (dense activation), supralinear $\mathrm{Ca}^{2+}$ responses spread throughout entire branchlets and can be supported entirely by voltage-dependent $\mathrm{Ca}^{2+}$ entry through the plasma membrane. In both cases, peak $\mathrm{Ca}^{2+}$ signals can exceed $10 \mu \mathrm{M}$, and hence are well within the range where $\mathrm{Ca}^{2+}$-sensitive intracellular kinases are activated ${ }^{31,32}$. Together with the similarity in timing dependence we observe for induction of LTD at PF synapses, our findings suggest that supralinear $\mathrm{Ca}^{2+}$ signals are the coincidence detection mechanism for LTD induction.

This discovery of a coincidence detection pathway involving 
Fig. 6. Timing dependence of spine signals and synaptic plasticity. (a) The PF-CF interval was defined as the interval between the first PF stimulus and the CF stimulus ( $\Delta \mathrm{t}$, left). The example shows an interval of $+300 \mathrm{~ms}$ (PF first). (b, c) $\left[\mathrm{Ca}^{2+}\right]$ responses to a range of timing conditions. Responses were defined as the 'transient response' in the $200 \mathrm{~ms}$ after the last stimulus (b) or the total integrated response (c; see Methods). Black trace, boxsmoothed average over three points. Gray curves, best fits of the raw data points to Gaussian functions. (d) Top, representative EPSPs taken before (thin trace) and after (thick trace) induction of long-term depression. Each trace represents the average of 20-30 sweeps. Bottom, mean time course of plasticity at PF synapses arising from conjunctive stimulation of CF and PF inputs. The CF and PF inputs were separated during the induction protocol by either - $150 \mathrm{~ms}$ (CF first, open symbols) or $+150 \mathrm{~ms}$ (PF first, closed symbols). Time courses are averages of 5- 6 experiments. (e) Relationship between synaptic plasticity and amplitude of spine $\left[\mathrm{Ca}^{2+}\right]$ responses under different experimental conditions. Transient spine $\left[\mathrm{Ca}^{2+}\right]$ response and change in PF-EPSP slope in response to SPFS alone $(\boldsymbol{\nabla})$, CF activation alone $(\boldsymbol{\square})$ and SPFS-CF coincidence $(\bullet)$; SPFS-CF $(O)$ and DPFS-CF $(\triangle)$ coincidence in thapsigargin.
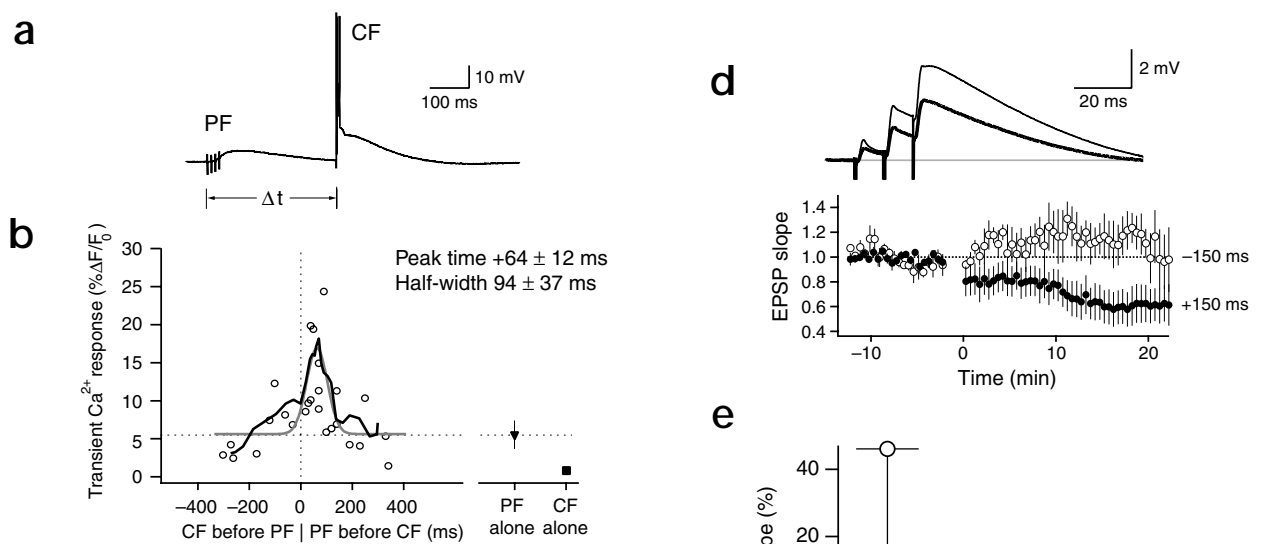

C

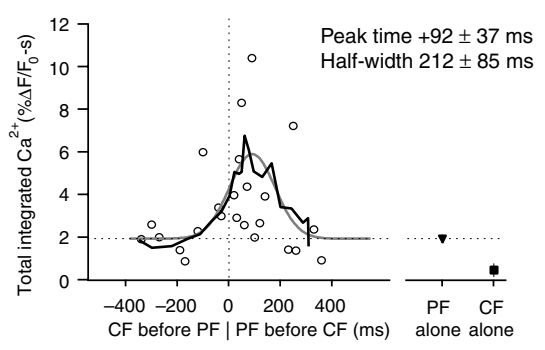

metabotropic glutamate receptors provides the first direct evidence that $\mathrm{IP}_{3}$ receptors mediate coincidence detection for cerebellar $\mathrm{LTD}^{7}$. Interestingly, mGluR coincidence detection requires activity in only a small number of PFs (indeed, a single active fiber may be sufficient) with a temporal firing pattern similar to that observed in vivo ${ }^{23}$. An important involvement of the metabotropic pathway is further supported by evidence from transgenic animals showing that mice lacking metabotropic receptors have deficient cerebellar synaptic plasticity and impaired motor learning ${ }^{18}$.

Pyramidal neurons, which possess NMDA receptor-dependent coincidence detection ${ }^{1}$, also display metabotropic coincidence detection ${ }^{33}$. Unlike in Purkinje cells, the mGluR-dependent $\mathrm{Ca}^{2+}$ signals observed so far in pyramidal neurons have a much larger spatial extent, and require many presynaptic fibers to be active at once $^{33}$, and thus may lack specificity for individual dendritic spines.

Remarkably, when the density of PF stimulation is increased, an entirely distinct mechanism that generates supralinear $\mathrm{Ca}^{2+}$ signals is recruited, based on $\mathrm{Ca}^{2+}$ entry through the plasma membrane. This coincidence mechanism no longer requires mGluR activation or release from intracellular stores, and because it is highly sensitive to hyperpolarization, it seems to rely on the voltage-dependence of $\mathrm{Ca}^{2+}$ channel activation. Because sodium action potentials do not backpropagate ${ }^{25,26}$ or generate $\left[\mathrm{Ca}^{2+}\right]$ transients ${ }^{15}$ in Purkinje cell dendrites, this supralinear activation of voltage-gated $\mathrm{Ca}^{2+}$ channels is likely to result from summation of depolarization generated at the PF spines by the respective $\mathrm{PF}$ and $\mathrm{CF}$ synaptic currents. Because the resulting $\mathrm{Ca}^{2+}$ signals fill entire branchlets (likely beyond the directly activated synaptic inputs), they represent a way for activity in a subset of PF spines on a branchlet to elevate $\left[\mathrm{Ca}^{2+}\right]$ in all the spines of that branchlet. Such a spread could explain the observation that LTD can spread from active to inactive synapses ${ }^{34,35}$. The physiologi- cal relevance of these voltage-dependent branchlet coincidence signals depends, however, on whether correlated activity normally occurs among neighboring PFs, for which there is yet no direct evidence (but see ref. 36). What is established is that the voltage-dependent mechanism can be readily activated during experimental stimulation of the PF pathway in vitro.

Our results may thus reconcile seemingly conflicting findings regarding the mechanisms of LTD induction (reviewed in ref. 4). Metabotropic receptor antagonists can block LTD induction ${ }^{17}$, but in several studies done at high PF stimulus intensities, LTD could still be induced ${ }^{37,38}$. Likewise, a previous report that thapsigargin fails to block LTD induction ${ }^{37}$ matches our finding at high, but not low PF stimulus intensities. We find that at low PF stimulus intensities, thapsigargin not only blocks LTD induction but unmasks a mild potentiation, an effect that may reflect a previously observed, mGluR-independent, presynaptic form of LTP ${ }^{39}$.

Our experiments show that the number and likely the spatial distribution of PF fibers activated are crucial in determining whether the coincidence-detection mechanism called into action is predominantly mediated by $\mathrm{Ca}^{2+}$ release from stores or $\mathrm{Ca}^{2+}$ influx through the plasma membrane. This dependence on the stimulus intensity may also be partly responsible for the seemingly inconsistent timing rules previously found for LTD induction $^{38,40,41}$. Another suggested locus for coincidence detection is a slow mGluR-mediated depolarization seen following coincident $\mathrm{PF}$ and CF stimulation ${ }^{10}$. We did observe this response (data not shown), but only at PF stimulus intensities far greater than those needed to evoke the $\mathrm{Ca}^{2+}$ responses reported here. Previous evidence regarding a requirement for the nitric oxide-cyclic GMP pathway and for activation of protein kinase $\mathrm{C}$ is also not inconsistent with our results, because these messengers might well act downstream of $\mathrm{Ca}^{2+}$ release $e^{4,38,42}$ or as necessary cofactors in LTD 
induction ${ }^{38}$. Alternatively, these signaling pathways may be recruited at higher levels of stimulation than those used in our study.

We have demonstrated that the supralinearity of the $\mathrm{Ca}^{2+}$ signal depends on the relative timing of the PF and CF inputs, further strengthening the view that timing is critical for the induction of synaptic plasticity. With weak PF stimuli, LTD occurs when PF bursts begin before CF firing ${ }^{43}$, consistent with our plasticity as well as our $\left[\mathrm{Ca}^{2+}\right]$ dynamics data. The lack of supralinearity when the CF precedes the PF burst is expected from a metabotropic mechanism for two reasons. First, neurotransmitter release from PFs shows a strong use-dependent facilitation ${ }^{44}$, causing greater glutamate release in response to bursts of activity, with glutamate concentrations peaking toward the end of a $\mathrm{PF}$ burst. Second, the dynamics of $\mathrm{IP}_{3}$ receptor activation suggest that LTD would depend on the temporal order of PF and CF activity. In particular, $\left[\mathrm{Ca}^{2+}\right]$ increases preceding $\mathrm{IP}_{3}$ formation inactivate the receptor ${ }^{45}$, which would make the total amount of $\mathrm{Ca}^{2+}$ release triggered by $\mathrm{IP}_{3}$ and $\mathrm{Ca}^{2+}$ dependent on the order at which the agonists arrive at the receptor. Other factors that could affect the timing window include messenger diffusion ${ }^{46}$ (M. H., G. Parésys \& W. D., Soc. Neurosci. Abstr. 23, 781.5, 1997), degradation ${ }^{47}$ and removal ${ }^{15}$, regulation of complex spike spread in the dendrite by inhibition ${ }^{48}$, and higher-order aspects of the temporal patterns of PF activity as they might occur in vivo. Some of these parameters may even be used to adapt the coincidence timing window to match biological requirements.

The timing rule- $\mathrm{PF}$ activity starting before CF firingobserved in our spine imaging and LTD experiments provides one way to link this cellular mechanism to behavioral phenomena. Studies of the vestibulo-ocular reflex ${ }^{49}$ show that the direction of the change in the reflex gain can be predicted very well from the correlation between simple spike firing rate and complex spike firing $100 \mathrm{~ms}$ later. These observations indicate that $\mathrm{PF}$ activity is required before CF firing (without having to make any assumptions regarding the delay from sensory input to neural activity), consistent with predictions from the Marr-Albus model of cerebellar cortical network function ${ }^{2}$.

An even more direct comparison between cellular and behavioral parameters is provided by eyeblink conditioning, where experiments have consistently shown that the conditional stimulus (CS; tone) must precede the unconditional stimulus (US; airpuff) by a minimum of $80 \mathrm{~ms}$ in order for associative learning to occur ${ }^{50}$. In this situation, the interval from sensory input to the neural response can be remarkably brief ${ }^{43}$ : US information is thought to be conveyed via the inferior olive and CF pathway, with a latency as short as $\sim 10 \mathrm{~ms}$ from stimulus onset, and the minimum delay from the CS to the onset of PF firing is similarly brief. This predicts that under conditions where learning takes place, $\mathrm{PF}$ firing would begin before $\mathrm{CF}$ firing, in accord with the conditions that generate both LTD and the largest singlespine $\mathrm{Ca}^{2+}$ signals in vitro.

\section{Methods}

Cerebellar brain slices. Standard techniques were used to prepare $300-\mu \mathrm{m}$ thick sagittal brain slices from the cerebellum of 17- to 25-day postnatal rats. Slices were incubated in a holding chamber at $30-32^{\circ} \mathrm{C}$ for $40-60 \mathrm{~min}$ and then returned to room temperature before recording. ACSF for slicing and incubation contained $124 \mathrm{mM} \mathrm{NaCl}, 3 \mathrm{mM} \mathrm{KCl}, 1 \mathrm{mM} \mathrm{NaH}_{2} \mathrm{PO}_{4}$, $1 \mathrm{mM} \mathrm{CaCl}_{2}, 2 \mathrm{mM} \mathrm{MgSO}_{4}, 26 \mathrm{mM} \mathrm{NaHCO}_{3}, 20 \mathrm{mM}_{\text {glucose and }}$ $0.02 \mathrm{mM}( \pm)$ aminophosphonovaleric acid (Tocris Cookson, Bristol, UK).

Electrophysiology. For recording, slices were transferred to a chamber, secured between two nylon nets, and perfused with recording ACSF at $28-33^{\circ} \mathrm{C}$ containing $124 \mathrm{mM} \mathrm{NaCl}, 3 \mathrm{mM} \mathrm{KCl}, 1 \mathrm{mM} \mathrm{NaH}{ }_{2} \mathrm{PO}_{4}$,
$2 \mathrm{mM} \mathrm{CaCl}_{2}, 1 \mathrm{mM} \mathrm{MgSO}_{4}, 26 \mathrm{mM} \mathrm{NaHCO}_{3}$ and $20 \mathrm{mM}$ glucose (305 mOsm). All experiments were performed at $28-33^{\circ} \mathrm{C}$. Whole-cell patch-clamp recordings were made from Purkinje neurons under visual control using oblique illumination and video contrast enhancement. Patch electrodes were made from borosilicate glass and pulled to a resistance of 7-10 M . Intracellular patch solution contained $133 \mathrm{mM}$ methanesulfonic acid (Fluka, Ronkonkoma, New York), $7.4 \mathrm{mM} \mathrm{KCl,} 0.3 \mathrm{mM} \mathrm{MgCl}$, $3 \mathrm{mM} \mathrm{Na}{ }_{2}$ ATP, $0.3 \mathrm{mM} \mathrm{Na}_{2} \mathrm{GTP}, \mathrm{pH}$ to 7.30 with $\mathrm{KOH}(285 \mathrm{mOsm})$; 0.25-0.5 mM Magnesium Green (Molecular Probes, Eugene, Oregon). Whole-cell current-clamp recordings were made using Axoclamp 2B amplifiers (Axon Instruments, Foster City, California). Neurons were held at $-65 \mathrm{mV}$ by injecting holding current; if the current exceeded $500 \mathrm{pA}$, cells were rejected. Bridge balance was adjusted periodically.

CF and PF inputs were stimulated (10-90 V, $0.2 \mathrm{~ms}$ ) with ACSF-filled patch pipettes placed, respectively, near the Purkinje cell body and beneath the filled dendritic arbor close to its lateral edge. Between trials, CFs were activated continuously at $0.1 \mathrm{~Hz}$ to simulate tonic CF firing in vivo and unpaired PF stimuli were delivered $1-2 \mathrm{~s}$ before a CF pulse. For timing experiments, the time interval between $\mathrm{PF}$ and CF stimuli was varied arbitrarily. Data from non-zero time interval trials were accepted only if zero time interval trials given before and afterward gave $\mathrm{Ca}^{2+}$ signals similar in size to one another, as determined in analysis after the experiment. To quantify the PF response, the amplitude of the second EPSP in the train was measured, because the paired-pulse facilitation at this synapse ${ }^{44}$ made this approach more reliable than measuring the first EPSP. For delivery of receptor antagonists, a 50- $\mu \mathrm{m}$ wide capillary tube (Polymicro Technologies, Phoenix, Arizona) was positioned at the surface of the slice before recording, and its back end was immersed in a reservoir of local perfusion solution containing $119 \mathrm{mM} \mathrm{NaCl}, 3 \mathrm{mM} \mathrm{KCl}, 1 \mathrm{mM} \mathrm{NaH}{ }_{2} \mathrm{PO}_{4}, 2 \mathrm{mM} \mathrm{CaCl}_{2}$, $1 \mathrm{mM} \mathrm{MgSO}_{4}, 25 \mathrm{mM}$ HEPES and $35 \mathrm{mM}$ D-glucose, $\mathrm{pH} 7.30$ with $\mathrm{NaOH}$. To this solution, $0.5-1 \mathrm{mM}(\mathrm{S})-4-\mathrm{CPG}$ (Tocris Cookson) or 20-50 $\mu \mathrm{M}$ DNQX (RBI, Natick, Massachusetts) were added. To start the flow of local solution, 5-10 psi of pressure were applied to the reservoir. Thapsigargin (Tocris Cookson) was applied via the bath perfusion and heparin (low molecular weight from porcine intestinal mucosa; Sigma, St. Louis, Missouri) was included at $50 \mu \mathrm{g} / \mathrm{mL}$ in the internal solution. Electrophysiology data were filtered at $1-2 \mathrm{kHz}$ and sampled at $10-20 \mathrm{kHz}$ using Clampex 7 or Axograph (Axon Instruments), and were analyzed using Clampfit 8 (Axon Instruments) or Igor Pro (WaveMetrics, Lake Oswego, Oregon). Chemicals were obtained from Sigma, Baker (Phillipsburg, New Jersey) or Fisher (Hampton, New Hampshire) unless otherwise indicated.

For plasticity experiments, PF strength was measured as the EPSP slope in response to 3 stimuli $(100 \mathrm{~Hz})$ delivered at $0.1 \mathrm{~Hz}$, as was the CF stimulus, at alternating 5-s intervals. Long-term depression was induced by halting the test stimuli and delivering 50 pairings at 2-s intervals. Each pairing was composed of $5 \mathrm{PF}$ stimuli $(100 \mathrm{~Hz})$ and $1 \mathrm{CF}$ stimulus. The amount of long-term depression was defined as the change in EPSP slope 20 min after pairing compared with a 10-min baseline immediately preceding pairing.

Two-photon microscopy. Two-photon fluorescence imaging was done using custom hardware and software (R. Stepnoski, Lucent Technologies). Pulses ( $100 \mathrm{fs}$ long, repeating at $80 \mathrm{MHz}$ ) from a Ti:sapphire laser (Tsunami, Spectra-Physics, Mountain View, California) tuned to $830 \mathrm{~nm}$ and pumped by a frequency doubled diode-pumped $\mathrm{Nd}$ :Vanadate laser (Verdi 5W, Coherent, Santa Clara, California) were directed through a Zeiss 63X water-immersion objective (NA 0.9; Carl Zeiss, Thornwood, New York). Fluorescence was detected in whole-area mode ${ }^{13}$ using an intensified photodiode (Intevac, Santa Clara, California) with a fluorescein emission filter. $\left[\mathrm{Ca}^{2+}\right]$ dynamics data were acquired using line scans (64 pixels/1 ms/line) or full field scans $(64 \mathrm{~ms})$ and were analyzed using Igor Pro. $\left[\mathrm{Ca}^{2+}\right]$ transients were estimated assuming an effective $\mathrm{K}_{\mathrm{D}}$ for $\mathrm{Ca}^{2+}$ of $19 \mu \mathrm{M}^{20,21}$ and $\mathrm{F}_{\max } / \mathrm{F}_{\min }=2$. Starting from low resting $\mathrm{Ca}^{2+}$, in the linear dye regime, this leads to a conversion factor of approximately $200 \mathrm{nM} \Delta\left[\mathrm{Ca}^{2+}\right]_{\mathrm{i}}$ per $\% \Delta \mathrm{F} / \mathrm{F}_{0}$.

Electrophysiological signals were recorded in the first few pixels of each scan line to ensure accurate registration with the optical signal. For placement of stimulating pipettes, a second detection channel was used for the transmitted infrared laser light. Responding spines could easily be identified by visual inspection of full-field fluorescence scans taken 
during coincident PF and CF stimulation. Supralinearity was defined as the ratio of the coincidence $\left[\mathrm{Ca}^{2+}\right]$ response to the sum of the responses to $\mathrm{PF}$ and $\mathrm{CF}$ stimulation alone. The transient $\left[\mathrm{Ca}^{2+}\right]$ response was defined as the mean fluorescence change relative to prestimulus baseline in the first $200 \mathrm{~ms}$ after the last synaptic stimulus. Supralinearity was, in addition, calculated for the total integrated $\left[\mathrm{Ca}^{2+}\right]$ response. Total integrated response was defined as the time integral of fluorescence change taken from the first synaptic stimulus to $500 \mathrm{~ms}$ after the last synaptic stimulus. Traces were filtered using a rolling time window of 30-60 ms. Statistical comparisons were made using one-tailed $t$-tests unless otherwise indicated. All values are given as mean \pm s.e.m.

\section{ACKNOWLEDGEMENTS}

We thank D.W. Tank for inspiration and suggestions, D. Attwell, A. Batchelor, K.I. Blum, S.G. Cull-Candy, B. Clark, B.E. Ehrlich, M. Farrant, M.S. Fee, F. Helmchen, K. Khodakhah, T.S. Otis, D.L. Pettit, A. Roth, R.A. Silver and R. Stepnoski for discussions, and A. Migala and M. Kaiser for technical assistance. S.S.-H.W. is supported by the Alfred P. Sloan Foundation and the Whitehall Foundation. M.H. is supported by grants from the Wellcome Trust and the European Union

\section{ReCEIVED 21 August; ACCEPTED 12 OCTOBER 2000}

1. Brown, T. H., Kairiss, E. W. \& Keenan, C. L. Hebbian synapses: biophysical mechanisms and algorithms. Annu. Rev. Neurosci. 13, 475-511 (1990).

2. Mauk, M. D., Garcia, K. S., Medina, J. F. \& Steele, P. M. Does cerebellar LTD mediate motor learning? Toward a resolution without a smoking gun. Neuron 20,359-362 (1998).

3. Ito, M. \& Kano, M. Long-lasting depression of parallel fiber-Purkinje cell transmission induced by conjunctive stimulation of parallel fibers and climbing fibers in the cerebellar cortex. Neurosci. Lett. 33, 253-258 (1982).

4. Daniel, H., Levenes, C. \& Crepel, F. Cellular mechanisms of cerebellar LTD. Trends Neurosci. 21, 401-407 (1998).

5. Sakurai, M. Calcium is an intracellular mediator of the climbing fiber in induction of cerebellar long-term depression. Proc. Natl. Acad. Sci. USA 87, 3383-3385 (1990).

6. Khodakhah, K. \& Armstrong, C. M. Induction of long-term depression and rebound potentiation by inositol trisphosphate in cerebellar Purkinje neurons. Proc. Natl. Acad. Sci. USA 94, 14009-14014 (1997).

7. Berridge, M. J. Cell signaling - a tale of two messengers. Nature 365, 388-389 (1993).

8. Iino, M. Biphasic $\mathrm{Ca}^{2+}$ dependence of inositol 1,4,5-trisphosphate-induced Ca release in smooth muscle cells of the guinea pig taenia caeci. J.Gen. Physiol. 95, $1103-1122(1990)$

9. Walton, P. D. et al. Ryanodine and inositol trisphosphate receptors coexist in avian cerebellar Purkinje neurons. J. Cell Biol. 113, 1145-1157 (1991).

10. Batchelor, A. M. \& Garthwaite, J. Frequency detection and temporally dispersed synaptic signal association through a metabotropic glutamate receptor pathway. Nature 385, 74-77 (1997).

11. Finch, E. A. \& Augustine, G. J. Local calcium signalling by inositol-1,4,5trisphosphate in Purkinje cell dendrites. Nature 396, 753-756 (1998).

12. Takechi, H., Eilers, J. \& Konnerth, A. A new class of synaptic response involving calcium release in dendritic spines. Nature 396, 757-760 (1998).

13. Denk, W., Sugimori, M. \& Llinás, R. Two types of calcium response limited to single spines in cerebellar Purkinje cells. Proc. Natl. Acad. Sci. USA 92, 8279-8282 (1995).

14. Blackstone, C. \& Sheng, M. Protein targeting and calcium signaling microdomains in neuronal cells. Cell Calcium 26, 181-192 (1999).

15. Miyakawa, H., Lev-Ram, V., Lasser-Ross, N. \& Ross, W. N. Calcium transients evoked by climbing fiber and parallel fiber synaptic inputs in guinea pig cerebellar Purkinje neurons. J. Neurophysiol. 68, 1178-1189 (1992).

16. Perkel, D. J., Hestrin, S., Sah, P. \& Nicoll, R. A. Excitatory synaptic currents in Purkinje cells. Proc. R. Soc. Lond. B Biol. Sci. 241, 116-121 (1990).

17. Hartell, N. A. Induction of cerebellar long-term depression requires activation of glutamate metabotropic receptors. Neuroreport 5, 913-916 (1994).

18. Conquet, F. et al. Motor deficit and impairment of synaptic plasticity in mice lacking mGluR1. Nature 372, 237-243 (1994).

19. Denk, W., Strickler, J. H. \& Webb, W. W. Two-photon laser scanning fluorescence microscopy. Science 248, 73-76 (1990).

20. Zhao, M., Hollingworth, S. \& Baylor, S. M. Properties of tri- and tetracarboxylate $\mathrm{Ca}^{2+}$ indicators in frog skeletal muscle fibers. Biophys. J. 70, 896-916 (1996).

21. Yuste, R., Majewska, A., Cash, S. S. \& Denk, W. Mechanisms of calcium influx into hippocampal spines: heterogeneity among spines, coincidence detection by
NMDA receptors, and optical quantal analysis. J. Neurosci. 19, 1976-1987 (1999). 22. Tank, D. W., Regehr, W. G. \& Delaney, K. R. A quantitative analysis of presynaptic calcium dynamics that contribute to short-term enhancement. J. Neurosci. 15, 7940-7952 (1995).

23. Merrill, E. G., Wall, P. D. \& Yaksh, T. L. Properties of two unmyelinated fibre tracts of the central nervous system: lateral Lissauer tract, and parallel fibres of the cerebellum. J. Physiol. (Lond.) 284, 127-145 (1978).

24. Tank, D. W., Sugimori, M., Connor, J. A. \& Llinás, R. R. Spatially resolved calcium dynamics of mammalian Purkinje cells in cerebellar slice. Science 242, 773-777 (1988).

25. Llinás, R. \& Sugimori, M. Electrophysiological properties of in vitro Purkinje cell dendrites in mammalian cerebellar slices. J. Physiol. (Lond.) 305, 197-213 (1980).

26. Stuart, G. \& Häusser, M. Initiation and spread of sodium action potentials in cerebellar Purkinje cells. Neuron 13, 703-712 (1994).

27. Eilers, J., Augustine, G. J. \& Konnerth, A. Subthreshold synaptic $\mathrm{Ca}^{2+}$ signalling in fine dendrites and spines of cerebellar Purkinje neurons. Nature 373, 155-158 (1995).

28. Eilers, J., Takechi, H., Finch, E. A., Augustine, G. J. \& Konnerth, A. Local dendritic $\mathrm{Ca}^{2+}$ signaling induces cerebellar long-term depression. Learn. Mem. 4, 159-168 (1997).

29. Maeda, H., Ellis-Davies, G. C. R., Ito, K., Miyashita, Y. \& Kasai, H. Supralinear $\mathrm{Ca}^{2+}$ signaling by cooperative and mobile $\mathrm{Ca}^{2+}$ buffering in Purkinje neurons. Neuron 24, 989-1002 (1999).

30. Thastrup, O., Cullen, P. J., Drobak, B. K., Hanley, M. R. \& Dawson, A. P. Thapsigargin, a tumor promoter, discharges intracellular $\mathrm{Ca}^{2+}$ stores by specific inhibition of the endoplasmic reticulum Ca2(+)-ATPase. Proc. Natl. Acad. Sci. USA 87, 2466-2470 (1990).

31. Schulman, H. \& Braun, A. in Calcium as a Cellular Regulator (eds. Carafoli, E. \& Klee, C. B.) 311-343 (Oxford Univ. Press, 1999).

32. Nakazawa, K., Mikawa, S. \& Ito, M. Persistent phosphorylation parallels longterm desensitization of cerebellar Purkinje cell AMPA-type glutamate receptors. Learn. Mem. 3, 578-591 (1997).

33. Nakamura, T., Barbara, J. G., Nakamura, K. \& Ross, W. N. Synergistic release of $\mathrm{Ca}^{2+}$ from $\mathrm{IP}_{3}$-sensitive stores evoked by synaptic activation of mGluRs paired with backpropagating action potentials. Neuron 24, 727-737 (1999).

34. Hartell, N. A. Strong activation of parallel fibers produces localized calcium transients and a form of LTD that spreads to distant synapses. Neuron 16, 601-610 (1996).

35. Wang, S. S.-H., Khiroug, L. \& Augustine, G. J. Quantification of spread of cerebellar long-term depression using chemical two-photon uncaging of glutamate. Proc. Natl. Acad. Sci. USA 97, 8635-8640 (2000).

36. Vos, B. P., Maex, R., Volny-Luraghi, A. \& De Schutter, E. Parallel fibers synchronize spontaneous activity in cerebellar Golgi cells. J. Neurosci. RC6, 1-5 (1999).

37. Hemart, N., Daniel, H., Jaillard, D. \& Crepel, F. Receptors and second messengers involved in long-term depression in rat cerebellar slices in vitro: a reappraisal. Eur. J. Neurosci. 7, 45-53 (1995).

38. Lev-Ram, V., Jiang, T., Wood, J., Lawrence, D. S. \& Tsien, R. Y. Synergies and coincidence requirements between $\mathrm{NO}, \mathrm{cGMP}$, and $\mathrm{Ca}^{2+}$ in the induction of cerebellar long-term depression. Neuron 18, 1025-1038 (1997).

39. Salin, P. A., Malenka, R. C. \& Nicoll, R. A. Cyclic AMP mediates a presynaptic form of LTP at cerebellar parallel fiber synapses. Neuron 16, 797-803 (1996).

40. Ekerot, C. F. \& Kano, M. Stimulation parameters influencing climbing fibre induced long-term depression of parallel fibre synapses. Neurosci. Res. 6, 264-268 (1989).

41. Schreurs, B. G. \& Alkon, D. L. Rabbit cerebellar slice analysis of long-term depression and its role in classical conditioning. Brain Res. 631, 235-240 (1993).

42. Ito, M. \& Karachot, L. Messengers mediating long-term desensitization in cerebellar Purkinje cells. Neuroreport 1, 129-132 (1990).

43. Schreurs, B. G., Oh, M. M. \& Alkon, D. L. Pairing-specific long-term depression of Purkinje cell excitatory postsynaptic potentials results from a classical conditioning procedure in the rabbit cerebellar slice. J. Neurophysiol. $75,1051-1060$ (1996).

44. Atluri, P. P. \& Regehr, W. G. Determinants of the time course of facilitation at the granule cell to Purkinje cell synapse. J. Neurosci. 16, 5661-5671 (1996).

45. Khodakhah, K. \& Ogden, D. Fast activation and inactivation of inositol trisphosphate-evoked $\mathrm{Ca}^{2+}$ release in rat cerebellar Purkinje neurones. J. Physiol. (Lond.) 487, 343-358 (1995).

46. Svoboda, K., Tank, D. W. \& Denk, W. Direct measurement of coupling between dendritic spines and shafts. Science 272, 716-719 (1996).

47. Wang, S. S., Alousi, A. A. \& Thompson, S. H. The lifetime of inositol 1,4,5trisphosphate in single cells. J. Gen. Physiol. 105, 149-171 (1995).

48. Callaway, J. C., Lasser-Ross, N. \& Ross, W. N. IPSPs strongly inhibit climbing fiber-activated $\left[\mathrm{Ca}^{2+}\right]_{\mathrm{i}}$ increases in the dendrites of cerebellar Purkinje neurons. J. Neurosci. 15, 2777-2787 (1995).

49. Raymond, J. L. \& Lisberger, S. G. Neural learning rules for the vestibulo-ocular reflex. J. Neurosci. 18, 9112-9129 (1998).

50. Gormezano, I., Kehoe, E. J. \& Marshall, B. S. in Progress in Psychobiology and Physiological Psychology (eds. Sprague, J. M. \& Epstein, A. N.) 197-275 (Academic, New York, 1983). 